\title{
Modelling of Highway Runoff Quantity and Quality
}

\author{
Ashraf El-Shahat Elsayed, A. Grünwald, M. Synáčková, M. Slavíček
}

The stormwater Management Model (SWMM) is a well-known stormwater runoff-simulation model. It is a deterministic, spatially distributed model for calculation of runoff quantity and quality. The aim of this study was to predict highway runoff characteristics using data from different highway catchments. The SWMM was used in the simulation process and the predicted data was verified using monitoring data collected from Prague-Plzeň highway for both total suspended solids and organic compounds. The analyzed data indicated that the simulated TSS, $\mathrm{BOD}_{5}$ concentrations lie within the range of the measured data and both data sets are considered highly polluted with respect to the specification limits. The analyzed data also show that the first flush of runoff is the most polluted, and is responsible for contamination of retention and/or received waters.

Keywords: Stormwater Management Model, highway runoff, quantity, quality, first flush.

\section{Introduction}

The accumulation of dust and dirt on the impervious surface of catchments such as highway surface may be attributed to numerous sources. Vehicles are a source of oil, petrol and eroded material from car bodies and tyres. Industry and transport are also sources of dust and gaseous material, which is emitted into the atmosphere and subsequently settles out or is washed out by rainfall. Assessment of the quantity and quality of stormwaters runs from the surface of these catchments can benefit from applying the Stormwater Management Model.

Models for simulation of stormwater quantity and quality vary widely in terms of their complexity and data, personnel, and computational requirements. The simplest models calculate pollutant loads from the storm runoff volume and event mean concentration (EMC). At the other extreme there are simulation models that attempt to simulate the buildup and washoff of pollutants from the watershed and their transport through the drainage system to the point of interest [3], [5].

The goal of this study is to predict highway runoff characteristics using data from different highway catchments. The Stormwater Management Model (SWMM) was used in the simulation process and the predicted data was verified using monitoring data collected from Prague-Plzeň highway. The analysis focused on total suspended solids (TSS), because they are widely viewed as an indicator of stormwater quality and are correlated with other stormwater quality constituents [6].

\section{Stormwater Management Model (SWMM)}

SWMM is a well-known stormwater runoff simulation model developed in the United States between 1969 and 1971. Since then it has been used in scientific and practical applications in many countries. The SWMM is a deterministic, spatially distributed model for calculation of runoff quantity and quality [4]. The input consists of a time series of rainfall data (and/or snowmelt) and a set of parameters describing the physical properties of the catchment. Structurally, the model can be divided in four main modules, which can run separately or combined together:

1. The RUNOFF Module is critical to SWMM simulation. This module receives meteorological data from user-de- fined hyetographs (rainfall intensity vs. time), antecedent conditions, land use and topography, and then simulates the rainfall-runoff process using a non-linear reservoir approach. Surface runoff is calculated from rainfall excess surface detention and evaporation. Quality processes in this module include generation of surface runoff constituent loads through a variety of options: a) buildup of constituents during dry weather and washoff during wet weather, b) the rating curve approach, in which the load is proportional to flow rate, and c) constant concentration. The RUNOFF Module produces hydrographs and pollutographs at inlet locations, which can be analyzed or used as an interface file to subsequent modules.

2. The TRANSPORT Module is the subsequent module, and performs the detailed flow and pollutant routing through the sewer system. The flow routing is accomplished using the kinematic wave method, while quality processes include first-order decay and simulating scour and deposition within the sewer system. The TRANSPORT Module uses inlet hydrographs and pollutographs generated either from the RUNOFF Module via an interface file or from the user defined option as the input. This module deals with flow quantity and quality, whereas the EXTRAN Module deals with flow quantity only.

3. The extended Transport (EXTRAN) Module provides the SWMM with dynamic wave simulation capability [5]. This module is the most comprehensive simulation program available in the public domain for drainage system hydraulics, and simulates branches or looped networks. The flow routing using this module is accomplished using the kinematic wave method.

4. The STORAGE/Treatment (S/T) Module was developed to simulate the routing of flows and pollutant through dryor wet- weather storage/treatment plants or units containing up to 5 units or processes. The primary objectives of the STORAGE/ Treatment Module are to: a) simulate the quality improvement provided by each process; b) simulate the handling of sludge; and c) provide estimates of capital, operation, and maintenance costs. The S/T Module simulates the removal of pollutant in the control devices by: First-order decay, Removal functions, and Sedimentation dynamics. 
In this study only the RUNOFF and TRANSPORT Modules will be used in the simulation of total solids (TS), and biochemical oxygen demands $\left(\mathrm{BOD}_{5}\right)$. The overland flow, buildup and washoff relationships, on which SWMM depends, will be discussed below.

\section{Buildup and washoff relationships}

The RUNOFF Module was developed to simulate both the quantity and quality of runoff in a drainage basin and the routing of flows and contaminants to the major sewer lines. It forms the source of runoff hydrographs and quality pollutographs for most SWMM applications.

Buildup and washoff relationships are physically based, and their use for simulating constituent concentrations is conceptually appealing. According to the buildup-washoff model, a supply of constituents is assumed to buildup on the land surface during periods of dry weather. With a subsequent storm, some of this material is then washed off into the drainage system. Buildup may depend on season, land use, traffic, and so forth. Washoff may be a function of rainfall intensity, bottom shear stress, and other factors.

Rates of buildup and various stormwater constituents on impervious surfaces have been measured in several studies. However, for some environments, stormwater data suggest that constituent buildup may not be correlated with the length of the antecedent dry period [7]. It also is likely that there is significant variation in the rate and maximum accumulation of constituents depending on climatic and other site-specific factors.

During a subsequent stormwater event, depending on stormwater duration and intensity, some or all of the constituents will be washed from the watershed with the storm runoff. The constituent will again accumulate during the dry days following the event, in addition to the amount of constituent load remaining on the watershed at the end of the previous storm event. Many stormwater models assume that the rate of washoff is a function of the amount of constituent present in the watershed. This formulation results in higher predicted concentration at the beginning of the storm event.

\section{Methodology}

To achieve the aim of this study, two types of data were used in the analysis process. These data include the simulated data using the SWMM model and the measured data from the in situ retention/detention units. The equations used in the prediction process using SWMM and the characteristics of the in situ retention/detention units are discussed in the following subsections.

\section{Simulated data}

SWMM can simulate both runoff quantities using the overland flow model and runoff quality using buildup-washoff models. The used equations will be discussed in the following.

\section{Overland flow model}

The RUNOFF Module forms the origin of flow generation with SWMM. In order to understand better the conversion of rainfall excess into overland flow (runoff), a brief description of the used equation is given. However, if the subcatchment width $(W)$ is assumed to represent a true prototype width of overland flow, then the reservoir will behave as a rectangular catchment, as sketched in Fig. 1.

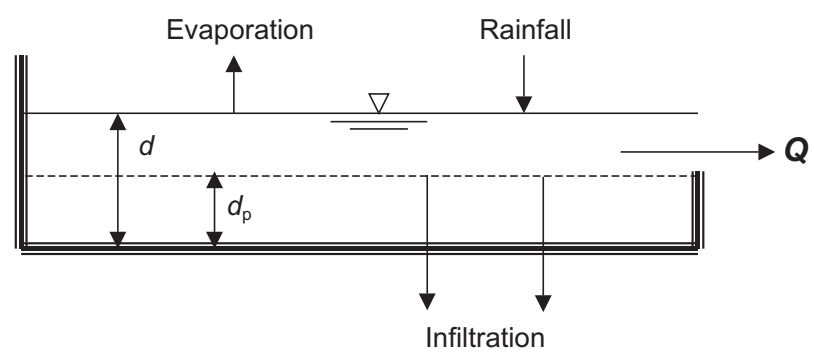

Fig. 1: Non-linear reservoir model for a subcatchment

The outflow is generated using Manning's equation as shown in Equation (1).

$$
Q=(W / n)\left(d-d_{p}\right)^{1.67} S^{0.5}
$$

where: $\quad Q=$ Outflow rate $\left[\mathrm{m}^{3} / \mathrm{s}\right]$,

$W=$ Subcatchment width $[\mathrm{m}]$,

$n$ = Manning's roughness coefficient,

$d=$ water depth $[\mathrm{m}]$,

$d_{\mathrm{p}}=$ depth of depression storage [m], and

$S=$ subcatchment slope $[\mathrm{m} / \mathrm{m}]$.

\section{Buildup model}

In the SWMM model, buildup and washoff of solids are both approximated using an exponential distribution. The distribution of buildup of solids is a function of the antecedent dry days, according to Equation (2).

$$
P_{\mathrm{t}}=P_{\mathrm{i}}+\left(P A-P_{\mathrm{i}}\right)\left(1-\mathrm{e}^{-\mathrm{kt}}\right)
$$

where: $\quad P_{\mathrm{t}}=$ accumulation of solids up to day $t[\mathrm{~kg}]$,

$P_{\mathrm{i}}=$ initial solids load on the surface (not washed from the previous storm) [kg],

$P=$ maximum buildup of solids $(2.4 \mathrm{~kg} / \mathrm{ha})$,

$A=$ drainage area $[\mathrm{ha}]$,

$k=$ exponential buildup factor (0.4) $\left[\right.$ days $\left.^{-1}\right]$, and

$t=$ antecedent dry days.

The maximum solids buildup load can be adjusted to provide similar long-term solids loading rates. In the SWMM model once the pollutant build-up reaches the maximum limit $(2.4 \mathrm{~kg} / \mathrm{ha})$, additional build-up is not allowed (assumed to be wind re-suspended/driven off the surface).

\section{Washoff model}

Washoff is the process of erosion or solution of constituents from a subcatchment surface during a period of runoff. If the water depth is more than a few millimeters, the process of erosion may be described by sediment transport theory in which the mass flow rate of sediment is proportional to the flow and bottom shear stress. Washoff is estimated using Equation (3).

$$
P_{\text {off }}=P_{\mathrm{t}}\left(1-\mathrm{e}^{-\mathrm{kv}}\right)
$$

where: $\quad P_{\text {off }}=$ cumulative amount washed off at time $t[\mathrm{~kg}]$,

$P_{\mathrm{t}}=$ initial amount of quantity on a surface calculated from Equation $1[\mathrm{~kg}]$,

$k=$ exponential decay factor $(0.2)\left[\mathrm{mm}^{-1}\right]$, and 
$v=$ volume of accumulated runoff from the surface $[\mathrm{mm}]$.

The exponential decay factor $(k)$ was based on a review of previous literature, which indicates that $k$-values range from 0.03 to $0.55 \mathrm{~mm}^{-1}[1]$.

\section{Modeling parameters}

SWMM model catchments and conveyance systems are based on input rain, temperature, and evaporation data. Only rain data were used in these analyses, while temperature and evaporation data were used as default values. Tab. 1 provides a list of the parameters used in the SWMM model.

Table 1: SWMM parameters

\begin{tabular}{|l|c|}
\hline \multicolumn{1}{|c|}{ Parameter } & Value \\
\hline Area [ha] & Variable \\
\hline Imperviousness & $100 \%$ \\
\hline Width $[\mathrm{m}]$ & Variable \\
\hline Slope & Variable \\
\hline Impervious depression Storage $[\mathrm{mm}]$ & 1.00 \\
\hline Impervious Manning's value $n$ & 0.011 \\
\hline Maximum Infiltration Rate $[\mathrm{mm} / \mathrm{hr}]$ & 25 \\
\hline Minimum Infiltration Rate $[\mathrm{mm} / \mathrm{hr}]$ & 6 \\
\hline Decay Rate of Infiltration $\left[\mathrm{s}^{-1}\right]$ & 0.00115 \\
\hline
\end{tabular}

The width of the subcatchment was assumed to be equal to the square root of the area.

\section{Measured data}

Different storage/sediment units along the Prague-Plzeň (D5) highway in the Czech Republic were selected for monitoring runoff from highways. The Prague-Plzeň (D5) highway

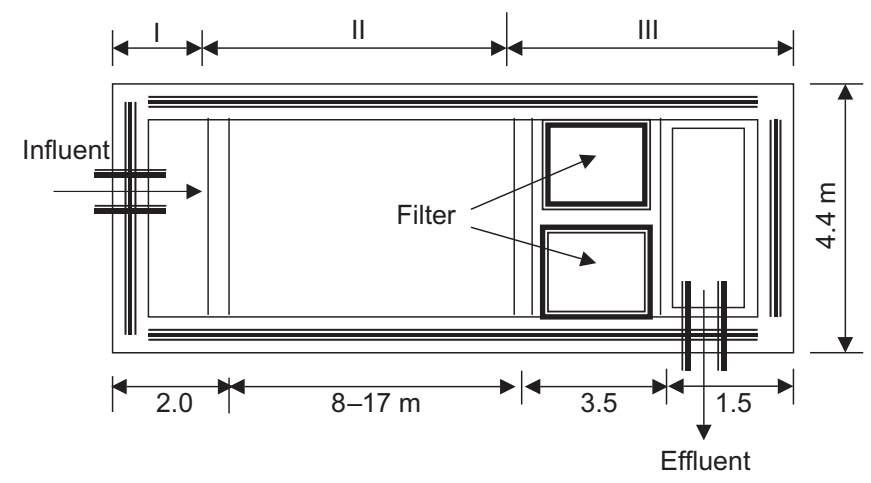

Fig. 2: Storage/sediment units.

is a divided 6-lane highway with average daily traffic (ADT) in the range 16000-22000 vehicles/day/both directions. These units, as shown in Fig. 2, collect runoff from a $100 \%$ impervious area (highway surface).

The tested sample was collected from the influent highway runoff into the monitored units. These samples were collected manually using metal bottles. Runoff samples for suspended solids and organic analysis were filtered through pre-weighed, pre-combusted glass fiber filters. After drying at $105^{\circ} \mathrm{C}$ temperature, the filters were re-weighed to determine the amount of suspended solids in each sample.

\section{Results and discussion}

This study used one-year and two-year rainfall data to predict the runoff quantity and quality process. This study evaluates the effect of these data on runoff volume and the concentration of total suspended solids (TSS), and biochemical oxygen demands $\left(\mathrm{BOD}_{5}\right)$. The results are analyzed in the following sections.

\section{Data verification}

Due to the shortage of measured data and the necessity to study some important concepts such as runoff peak flow, pollutant accumulation and first flush phenomena, simulated data were used for studying these concepts. Then, the simulated data were verified with available measured data to measure the confidence in these simulated data. A comparison between the measured and simulated concentrations of some constituents is shown in Tab. 2. The results indicate that the concentration of TSS and $\mathrm{BOD}_{5}$ is very close to those measured from the D5 highway in Czech Republic, and the results lie within the total range of measured data. The simulated data therefore has a degree of confidence. With this confidence degree the studied concepts can be accepted and analyzed.

\section{Quantity simulation}

The overflow volume and the time of the discharged peak overflow will be analyzed in this section. The used rainfall data hyetograph and the accumulated runoff volume are shown in Fig. 3. The ŠIFALDA rainfall data hyetograph was used, and the measured intensity values were recorded at a rainfall station near the studied area. The effect of these data on peak flow at the sewer system outlet is also shown in Fig. 3. The figure indicates that the runoff volume increases as either the subcatchment area increases or the rainfall intensity increases under the effect of the same conditions. Consequently, the diameter of the conveyance system, which was designed for maximum flow less than full flow, should be increased depending on the runoff volume. The figure also shows that the runoff peak flow value increases as rainfall intensity increases and this occurs approximately at the same time after the beginning of a storm event. The value and the time of peak flow affects the design of retention/detention units.

Table 2: Comparison between simulated and measured data

\begin{tabular}{|c|c|c|c|c|c|c|}
\hline \multirow{2}{*}{ Constituents } & \multicolumn{4}{|c|}{ Measured Data } & \multicolumn{2}{|c|}{ Simulated Data } \\
\hline & SSUD 8 & Drahelčice & SSUD 9 & Rokycany & Average & Range \\
\hline TSS $[\mathrm{mg} / \mathrm{l}]$ & 221 & 4895 & 5601 & 1969 & 1250 & $200-1650$ \\
\hline $\mathbf{B O D}_{5}[\mathrm{mg} / \mathrm{l}]$ & 3.21 & 18.25 & 2.65 & 4.20 & 6.88 & $6.00-8.20$ \\
\hline
\end{tabular}



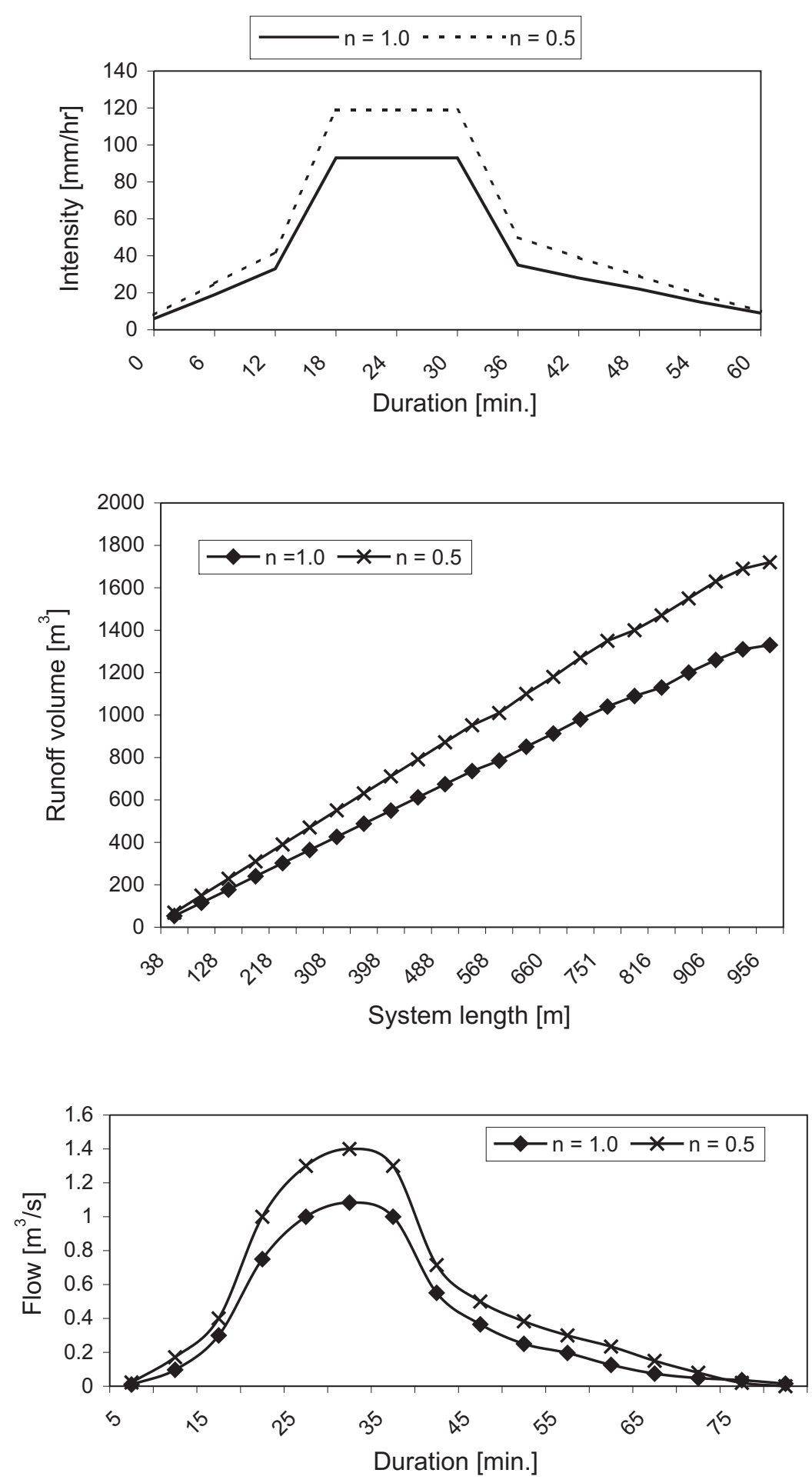

Fig. 3: Relationship between rainfall intensity and flow characteristics

\section{Quality simulation}

The buildup process is a function of antecedent dry days, traffic volume, and seasonal considerations, whereas washoff is the process of removing contaminants from the subcatchment surface during a period of runoff. TSS and $\mathrm{BOD}_{5}$ contaminations that washed off the pavement surface and were transported into the sewer system are simulated at the outlet, as shown in Fig. 4 and 5. The figures indicate that the load of TSS and $\mathrm{BOD}_{5}$ increase as the rainfall intensity increases. The higher load of TSS as well as $\mathrm{BOD}_{5}$ is explained by the intensity of the rainfall. Higher flow rates, associated with higher rainfall intensity, moved more of the heavier dirt particles than smaller storm events did. The contaminations 

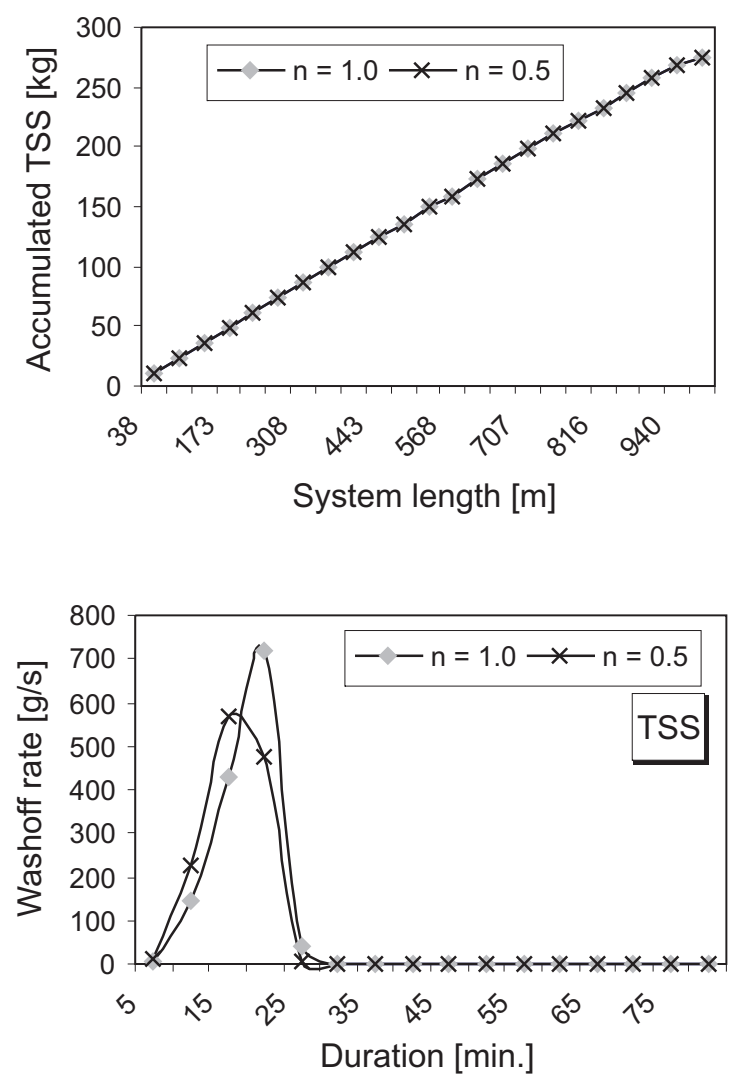

Fig. 4: Loads of TSS washed from highway

deposited during a dry period preceding the rainwater and the washed off contaminations during a storm event contribute to the total measured contamination in the runoff. The figure also shows that the peak rate value and time is higher for one-year rainfall data than for two-year rainfall data. This may be due to the high runoff volume with two-year rainfall data which Wash off most of the pollutant in the early stages of runoff.

\section{First flush}

The first flush is an important phenomenon for receiving water impacts. A period of high concentration is evident for each constituent at the beginning of the storm. The period of high concentration, however, occurs simultaneously with the rising leg of the hydrograph and ends at the time of concentration for the watershed. It is difficult to ascertain from the graph if the high concentration at the beginning of the storm results from a large amount of material being washed from the highway early in the storm event (e.g., a true first flush) or from the smaller volume of water in the catchment (watershed) at the start of the storm. The nature of the contaminants and their solubilities in water may affect the magnitude and extent of the first flush effect.

Fig. 6 shows the relationship between runoff volume and scoured/washed off concentrations. As shown in the figure, the deposited contaminations on the pavement surface are scoured in the first stages of a rain event or at least that its concentrations decrease with time. The figure shows that the
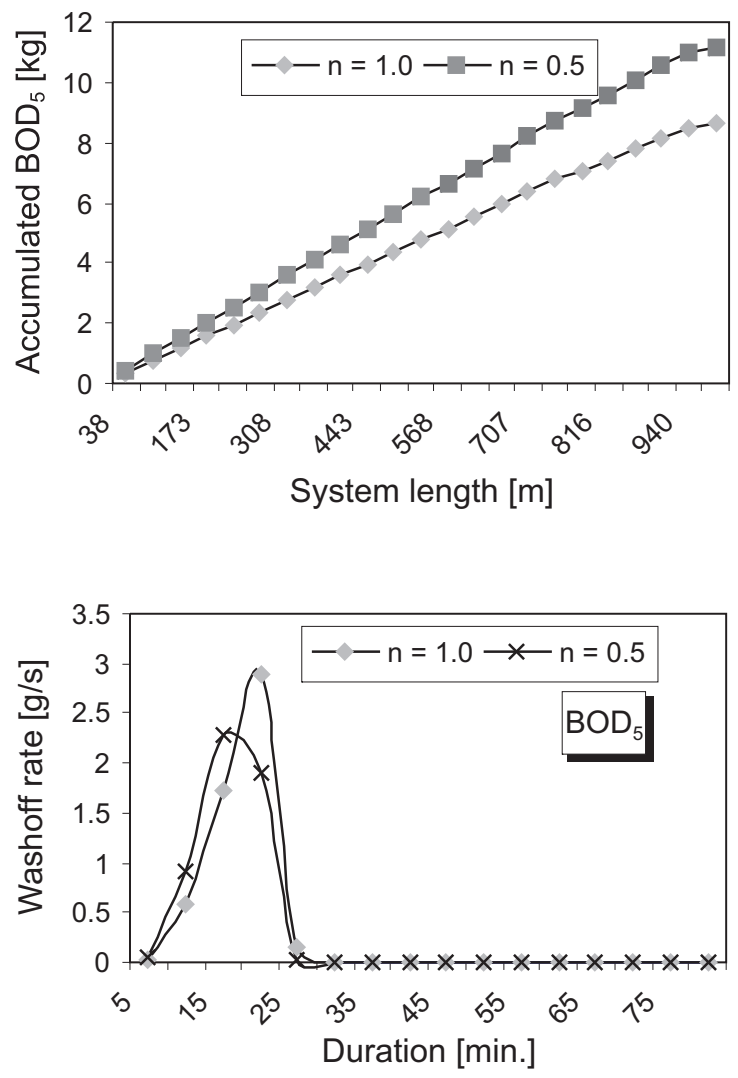

Fig. 5: Loads of $\mathrm{BOD}_{5}$ washed from highway

contamination is totally washed off at less than half of the overflow rate duration, and this explains what happens during the first flush.

The simulated data was in agreement with various other studies, which show that the concentration of runoff contaminations is high in the first runoff flow during a storm event. This means that most of the surface contamination is washed off in the early stages of a storm event, depending on the intensity of the storm. Consequently the concentration of the contaminations decreases with increasing storm duration and runoff volume. Tab. 3 shows the concentration of TSS and $\mathrm{BOD}_{5}$ for different measured flow volumes investigated in this study.

Table 3: Percent of washed off contaminations versus total loads of these contaminations using 1-year rainfall data

\begin{tabular}{|l|c|c|c|}
\hline \multirow{2}{*}{$\begin{array}{c}\text { Measured } \\
\text { Constituents }\end{array}$} & \multicolumn{3}{|c|}{ Percent of Runoff Volume of Runoff } \\
\cline { 2 - 4 } & $10 \%$ & $43 \%$ & $76 \%$ \\
\hline TSS $[\mathrm{mg} / \mathrm{l}]$ & 75.68 & 98.70 & 99.0 \\
\hline BOD $_{\mathbf{5}}[\mathrm{mg} / \mathrm{l}]$ & 74.89 & 98.0 & 99.0 \\
\hline
\end{tabular}

\section{Conclusion}

Assessment of stormwater quantity and quality runs from the surface of a catchment can benefit from applying the Stormwater Management Model. The Stormwater Manage- 

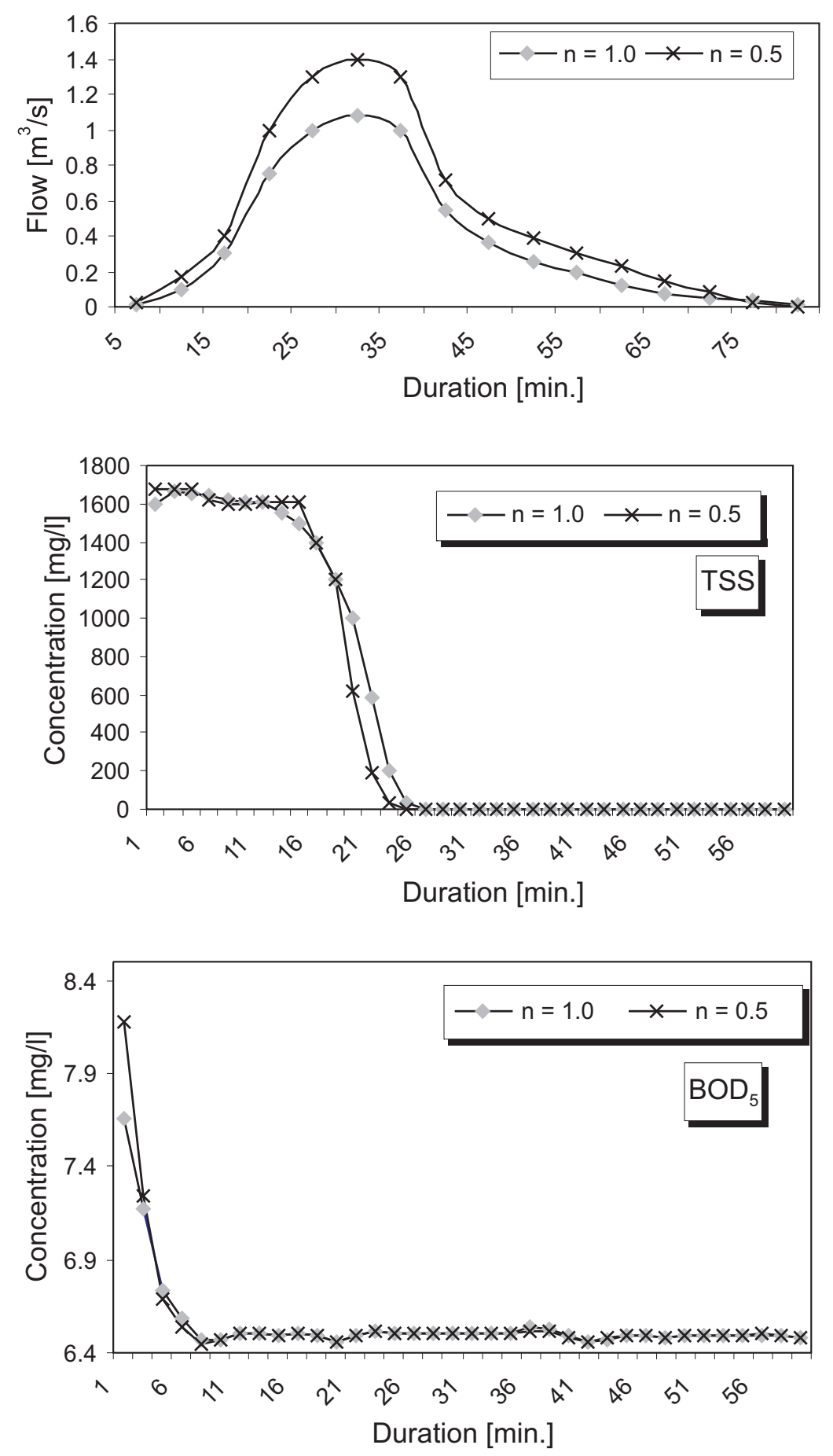

Fig. 6: First flush phenomena

ment Model (SWMM) is a well-known stormwater runoff-simulating model. The SWMM was used in a simulation process and the predicted data were verified using measured data collected from the Prague-Plzeň highway for both total suspended solids and biochemical oxygen demands. The analysis of the results indicates that the SWMM makes a useful prediction of both runoff quality and runoff quantity. The simulated results were compared and verified using measured data from the Prague-Plzeň highway, Czech Republic. The verification of the data indicates that the simulated data are very close to the measured data, and this gives a high degree of confidence in the simulation process. Using SWMM results, the effect of first flush concentration on a receiving water and/or on a retention unit can be evaluated to choose BMPs suitable for the studied conditions. Peak flow volume and duration are required for the design of retention units.

\section{Acknowledgement}

We would like to thank and express our appreciation to Ing. Kateřina Slavíčková for her endless help. This Research has been supported by grant No.: VZ J04198: 2111100005. 


\section{References}

[1] Charbeneau, R., Barrett, M.: Evaluation of Methods for Estimating Stormwater Pollutant Loads. Water Environment Research, Vol. 70, No. 7/1998

[2] Davies, T. T.: SWMM Windows Interface User's Manual 4.3. Office of Water, EPA-823-B-95-008, United States Environmental Protection Agency, 1995

[3] Huber, W. C., Dickinson, R. E.: Stormwater Management Model Version 4, User's Manual. EPA-600/3-88-001a, USEPA, Athens, Ga, 1988

[4] Niemczynowicz, J.: Mathematical Modeling. Department of Water Resources Engineering, University of Lund, Sweden, 1984

[5] Roesner, L. A., Adrich, J. A., Dickinson, R. E.: Stormwater Management Model Version 4, User's Manual. EPA-600/3-88-001a, USEPA, Athens, Ga, 1988

[6] Sansalone, J. J., Buchberger, S. G.: Partitioning and First Flush of Metals in Urban Roadway Stormwater. Environmental Engineering, 1997, pp. 123-134
[7] Sutherland, R. C., Jelen S. L.: Sophisticated Stormwater Quality Modeling Is Worth The Effort. In Advances In Modeling The Management of Stormwater Impacts, W. James, CHI, Guelph, Ca, 1995

B.Sc. Ashraf El-Shahat Elsayed, MSc e-mail: ashraf@fsv.cvut.cz

Prof. Ing. Alexander Grünwald, CSc. phone: +420224354638 e-mail: grunwald@fsv.cvut.cz

Ing. Marcela Synáčková, CSc. phone: +420224354604 e-mail: synackov@fsv.cvut.cz

Ing. Marek Slavíček

phone: +420224354608

e-mail: marek.slavicek@fsv.cvut.cz

Department of Sanitary Engineering

Czech Technical University in Prague

Faculty of Civil Engineering

Thákurova 7, 16629 Praha 6, Czech Republic 